\title{
Radioanalytical Chemistry for
}

\section{Automated Nuclear Waste Process Monitoring}

\author{
FINAL REPORT
}

Principle Investigators:

Dr. Jay W. Grate

Phone: (509) 376-4242

Fax: (509) 376-5106

E-mail: jwgrate@pnl.gov

Pacific Northwest National Laboratory, K8-93 Box 999,

Richland, WA 99352

Dr. Timothy A. DeVol

Phone: (864) 656-1014

Fax: (864) 656-0672

E-mail: tim.devol@,ces.clemson.edu

Environmental Engineering \& Science

Clemson University

Clemson, SC 29634-0919 


\section{Introduction}

The objectives of our research were to develop the first automated radiochemical process analyzer including sample pretreatment methodology, and to initiate work on new detection approaches, especially using modified diode detectors.

Early in the program we saw the opportunity to insert new technology into the decision processes for the Hanford Waste Treatment Plant, provided that we could develop the first analyzer fast enough, and do so for determination of total Tc in chemical processing streams at Hanford. Technetium-99 is a radionuclide of significant concern in nuclear waste processing. It is important to immobilize it in stable waste forms because of its high abundance in aged nuclear waste from weapons production, it long halflife, and its mobility (as pertechnetate, ${ }^{99} \mathrm{Tc}(\mathrm{VII})$ ) in the environment if not contained. Therefore, a large portion of our effort in the first phase was to demonstrate and validate a total Tc analyzer approach. This effort was successful, and this technology was selected in a competitive peer-reviewed process for the Hanford Waste Treatment Plant, currently under construction on the Hanford site. Development of the total Tc analyzer is therefore is a main topic of our final report. Our EMSP funding enabled development of the analyzer concept and resolution of chemistry issues for sample pretreatment and Tc separation within the instrument, while applied funding from the Hanford site supported engineering development of the prototype and testing with full QA/QC documentation to support the decision process. In parallel we also conducted research on detection methodology at PNNL and at Clemson.

Because of the close interaction between the two research groups and the over lap in some of the methodologies used in the research, this final report is based on two joint EMSP projects conducted by the Pacific Northwest National Laboratory and Clemson University. In total, these projects spanned six years. The sections below summarize some of the outcomes of this collaborative research effort.

\section{FUNDING}

Radionuclide Sensors for Water Monitoring, proposal and renewal, 6 years total. This work could not be renewed after FY05 due to the changed focus of the EMSP vadose zone program.
PNNL:
FY00, 01, 02, \$200K per year
FY03, 04, $05 \$ 206 \mathrm{~K}$ per year

Clemson:

FY00, 01, 02, \$75K per year

FY03, 04, $05 \$ 80 \mathrm{~K}$ per year

Radioanalytical Chemistry for Automated Nuclear Waste Process Monitoring, proposal and renewal. This work was canceled beyond FY06 with the elimination of the EMSP high level waste program.

PNNL: $\quad$ FY02, 03, 04 \$233K per year $\quad$ FY05, 06 \$240K per year (2 yrs only)

Clemson FY02, 03, 04 \$117K per year FY05, 06 \$100K per year (2 yrs only)

\section{PRODUCTIVITY}

\section{Publications}

1. Egorov, O.B., M.J. O'Hara, and J.W. Grate, Equilibration-Based Preconcentrating Minicolumn Sensors for Trace Level Monitoring of Radionuclides and Metal Ions in Water without Consumable Reagents. Anal. Chem., 2006. Accepted.

2. Hughes, L.D. and T.A. DeVol, Evaluation of flow cell detector configurations combining simultaneous preconcentration and scintillation detection for monitoring of pertechnetate in aqueous media. Anal.Chem., 2006. 78(7): p. 2254-2261. 
3. Hughes, L.D. and T.A. DeVol, Characterization of a Teflon (R) coated semiconductor detector flow cell for monitoring of pertechnetate in groundwater. J. Radioanal. Nucl. Chem., 2006. 267(2): p. 287-295.

4. Roane, J.E. and T.A. DeVol, Evaluation of an extractive scintillation medium for the detection of uranium in water. J. Radioanal. Nucl. Chem., 2005. 263(1): p. 51-57.

5. Hughes, L.D., B.A. Powell, A.M. Soreefan, D.A. Falta, and T.A. DeVol, Anomalously high levels of uranium and other naturally occurring radionuclides in private wells in the piedmont region of South Carolina. Health Physics, 2005. 88(3): p. 248-252.

6. Fjeld, R.A., T.A. DeVol, J.D. Leyba, and A. Paulenova, Measurement of radionuclides using ion chromatography and on-line radiation detection. Journal of Radioanalytical and Nuclear Chemistry, 2005. 263(3): p. 635-640.

7. Egorov, O.B., M.J. O'Hara, J.W. Grate, M. Knopf, G. Anderson, and J. Hartman, Radiochemical Sensor System for the Analysis of 99Tc(VII) in Groundwater. J. Radioanal. Nucl. Chem., 2005. 264: p. 495-500.

8. Egorov, O.B., R.S. Addleman, M.J. O'Hara, T. Marks, and J.W. Grate, Direct measurement of alpha emitters in liquids using passivated ion implanted planar silicon (PIPS) diode detectors. Nuclear Instruments \& Methods in Physics Research, Section A: Accelerators, Spectrometers, Detectors, and Associated Equipment, 2005. 537(3): p. 600-609.

9. Egorov, O., M.J. O'Hara, and J.W. Grate, Automated Radiochemical Analysis of Total Tc-99 in Aged Nuclear Waste Processing Streams. J. Radioanal. Nucl. Chem., 2005. 263: p. 629-633.

10. Addleman, R.S., M.J. O'Hara, T. Marks, J.W. Grate, and O.B. Egorov, Direct actinide assay with surface passivated silicon diodes. J. Radioanal. Nucl. Chem., 2005. 263(2): p. 295-300.

11. Addleman, R.S., M.J. O'Hara, J.W. Grate, and O.B. Egorov, Chemically enhanced alpha-energy spectroscopy in liquids. J. Radioanal. Nucl. Chem., 2005. 263(2): p. 291-294.

12. Addleman, R.S., O.B. Egorov, M.J. O'Hara, B. Busche, T.S. Zemanian, and G. Fryxell, Preconcentration and assay of radionuclides with self assembled monolayers on mesoporous supports. Journal of Radioanalytical and Nuclear Chemistry, 2005. 263(1): p. 59-64.

13. Grate, J.W., O.B. Egorov, and M.J. O'Hara, Sensors and Automated Analyzers for Radionuclides. ACS Symposium Series, 2004. 904(Subsurface Contamination Remediation): p. 322-341.

14. Fjeld, R.A., J.E. Roane, J.D. Leyba, A. Paulenova, and T.A. DeVol, Sequential and simultaneous radionuclide separation-measurement with flow-cell radiation detection, in Radioanalytical Methods in Interdisciplinary Research. 2004. p. 105-119.

15. Egorov, O.B., M.J. O'Hara, and J.W. Grate, Microwave-Assisted Sample Treatment in a Fully Automated Flow-Based Instrument: Oxidation of Reduced Technetium Species in the Analysis of Total Technetium-99 in Caustic Aged Nuclear Waste Samples. Anal. Chem., 2004. 76: p. 38693877.

16. Egorov, O.B., M.J. O'Hara, R.S. Addleman, and J.W. Grate, Automation of radiochemical analysis: From groundwater monitoring to nuclear waste analysis. ACS Symposium Series, 2004. 868(Radioanalytical Methods in Interdisciplinary Research): p. 246-270.

17. Ayaz, B. and T.A. DeVol, Experimental-theoretical response of a $\mathrm{ZnS}(\mathrm{Ag}$ ) scintillating disc for gross-alpha measurements of aqueous radioactivity. Ieee Transactions on Nuclear Science, 2004. 51(4): p. 1688-1692.

18. Theisen, C.D., T.A. DeVol, and D.P. DiPrete, Quantification of quench on alpha/beta pulse shape discrimination of liquid scintillation cocktails. Health Physics, 2003. 84(6): p. S167-S168.

19. Tan, H. and T.A. DeVol, Monte Carlo modeling of heterogeneous scintillation flow-cell detectors. Nuclear Instruments \& Methods in Physics Research Section a-Accelerators Spectrometers Detectors and Associated Equipment, 2003. 515(3): p. 624-633.

20. Roane, J.E., T.A. DeVol, J.D. Leyba, and R.A. Fjeld, The use of extraction chromatography resins to concentrate actinides and strontium from soil for radiochromatographic analyses. Journal of Environmental Radioactivity, 2003. 66(3): p. 227-245. 
21. Hughes, L. and T.A. DeVol, On-line gross alpha radiation monitoring of natural waters with extractive scintillating resins. Nuclear Instruments \& Methods in Physics Research Section aAccelerators Spectrometers Detectors and Associated Equipment, 2003. 505(1-2): p. 435-438.

22. Grate, J.W. and O.B. Egorov, Automated Radiochemical Separation, Analysis, and Sensing, in Handbook of Radioactivity Analysis (2nd Ed.). 2003, Elsevier. p. 1129-1164.

23. Ayaz, B. and T.A. DeVol, Application of MnO2 coated scintillating and extractive scintillating resins to screening for radioactivity in groundwater. Nuclear Instruments \& Methods in Physics Research Section a-Accelerators Spectrometers Detectors and Associated Equipment, 2003. 505(1-2): p. 458-461.

24. Tan, H. and T.A. DeVol, Development of a flow-cell alpha detector utilizing microencapsulated CsI : Tl granules and silicon PIN-photodiodes. Ieee Transactions on Nuclear Science, 2002. 49(3): p. 1243-1248.

25. Roane, J.E. and T.A. DeVol, Simultaneous Separation and Detection of Actinides in Acidic Solutions Using an Extractive Scintillating Resin. Anal. Chem., 2002. 74(21): p. 5629-5634.

26. Egorov, O., M.J. O'Hara, and J.W. Grate. Radionuclide selective sensors for water monitoring: 99Tc(VII) detection in Hanford groundwater. in Spectrum 2002:. 2002. Reno, NV: American Nuclear Society, La Grange Park, Ill.

27. DeVol, T.A., A.H. Ringberg, and R.A. Dewberry, Isotopic analysis of plutonium using a combination of alpha and internal conversion electron spectroscopy. Journal of Radioanalytical and Nuclear Chemistry, 2002. 254(1): p. 71-79.

28. Fjeld, R.A., T.A. DeVol, R.W. Goff, M.D. Blevins, D.D. Brown, S.M. Ince, and A.W. Elzerman, Characterization of the mobilities of selected actinides and fission/activation products in laboratory columns containing subsurface material from the Snake River Plain. Nuclear Technology, 2001. 135(2): p. 92-108.

29. Egorov, O.B., M.J. O'Hara, O.T. Farmer, III, and J.W. Grate, Extraction chromatographic separations and analysis of actinides using sequential injection techniques with on-line inductively coupled plasma mass spectrometry (ICP MS) detection. Analyst, 2001. 126(9): p. 1594-1601.

30. DeVol, T.A., O.B. Egorov, J.E. Roane, A. Paulenova, and J.W. Grate, Extractive scintillating resin for 99Tc quantification in aqueous solutions. J. Radioanal. Nucl. Chem., 2001. 249(1): p. 181-189.

31. DeVol, T.A., J.M. Duffey, and A. Paulenova, Combined extraction chromatography and scintillation detection for off-line and on-line monitoring of strontium in aqueous solutions. $\mathrm{J}$. Radioanal. Nucl. Chem., 2001. 249(2): p. 295-301.

32. Coates, J.T., R.A. Fjeld, A. Paulenova, and T. DeVol, Evaluation of a rapid technique for measuring actinide oxidation states in a ground water simulant. Journal of Radioanalytical and Nuclear Chemistry, 2001. 248(2): p. 501-506.

33. Tan, H., T.A. DeVol, and R.A. Fjeld, Digital alpha/beta pulse shape discrimination of CsI : T1 for on-line measurement of aqueous radioactivity. Ieee Transactions on Nuclear Science, 2000. 47(4): p. 1516-1521.

34. DeVol, T.A., J.E. Roane, J.M. Williamson, J.M. Duffey, and J.T. Harvey, Development of scintillating extraction media for separation and measurement of charged-particle-emitting radionuclides in aqueous solutions. Radioact. Radiochem., 2000. 11(1): p. 34-46. 


\section{Doctorate Theses}

Roane, J.E., (Ph.D.), "Radionuclide Separation using Coupled Chromatographic and Scintillation Detection Techniques", (August, 2001).

Tan, H., (Ph.D.), "Measurement of Radioactivity in Aqueous Solutions by Heterogeneous Scintillation Detection with Comparison to Stochastic Models", (May 2002).

Hughes, L.D. (Ph.D.), "Radionuclide Sensors for Monitoring of ${ }^{99} \mathrm{TcO}_{4}{ }^{-}$in Aqueous Solutions: Characterization of Detector Configurations and Data Analysis Methods", (May 2006).

\section{Masters Theses}

Drumm, L., (M.S.) "Gross Alpha-Radiation Monitoring of Natural Waters," (May 2002).

Chandrikamohan, P. (M.S.) "Comparison of Pulse Shape Discrimination Methods for BC400/BGO Phoswich and CsI:Tl Detectors," December 2004.

Soreefan, A. (M.S.) "Experimental and Monte Carlo Investigation of the Light Collection Efficiency of Heterogeneous Scintillation Flow Cell Detectors," non-thesis option August 2003.

Lolap, G. (M.S.) " CsI:T1 Temporal Luminosity Dependence on Radiation type and Energy", May 2006. 


\section{Integrated Analyzer Instrumentation}

Overall approach. Using the approach given in Figure 1, we focused on automated sample treatment necessary to convert nuclear waste process samples in the as-received matrix to samples containing the analyte in a suitable speciation and matrix for the subsequent automated separation and analysis. Focusing initially on the determination of total ${ }^{99} \mathrm{Tc}$ in caustic aged nuclear waste, we developed fully-automated microwave-assisted sample acidification and oxidation procedures using peroxydisulfate that enable rapid and reliable conversion of the reduced form of ${ }^{99} \mathrm{Tc}$ to ${ }^{99} \mathrm{Tc}(\mathrm{VII})$, i.e. pertechnetate. Separation chemistries to quantitatively capture and purify total Tc require that the Tc be in the pertechnetate state; nonpertechnetate species are not retained by anion exchange, extraction chromatographic or sorbent extraction materials useful in the analytical separation of ${ }^{99} \mathrm{Tc}$.[1-8] This sample treatment system and separation is part of an integrated ${ }^{99} \mathrm{Tc}$ automated radiochemical analyzer system that processes and analyzes nuclear waste samples in 15 minutes or less, using anion exchange chemistry to separate Tc from other radioactive species and a flow through solid scintillator detector. The effectiveness of the automated instrumentation and sample treatment procedures was demonstrated using actual aged nuclear waste solutions with high content of organic and nonpertechnetate species.

\section{Sample Matrix Modification and Speciation Control for Total Tc. Approach}

- Determine oxidizing conditions and matrix modification necessary to obtain rapid and effective oxidation of Tc to pertechnetate and resulting in a matrix suitable for subsequent separation.

- Develop an apparatus for rapid automated sample pretreatment chemistry using microwaveassisted digestion in an open vessel format.

- Overcome difficulties with uneven heating, violent bumping, gas evolution, foaming, and precipitate formation in digesting these complex sample matrices.

\section{Successes}

- We selected peroxydisulfate chemistry with prior sample acidification and demonstrated rapid, quantitative ${ }^{99} \mathrm{Tc}$ speciation control in automated format.

- Sample acidification has a number of benefits including: the kinetics of oxidation of organic compounds by peroxydisulfate are more rapid in acidic solutions.[9] Acidification provides sample matrix compatible with subsequent separation procedures; acidification copes with precipitates that would interfere with automated fluidic procedures; and using nitric acid eliminates sample reduction capacity due to nitrite by converting it to $\mathrm{HNO}_{2}$ which is unstable in acid media and rapidly decomposes at elevated temperatures.[10].

- An open vessel microwave digestion method was developed that allows multistep reagent additions, provides for continuous sample mixing using a bubbling nitrogen stream, while allowing evolved gases to escape. Without sample agitation, excessive violent boiling and sporadic sparking were observed.

- Quantitative recovery of sample from the digestion vessel was demonstrated and effective procedures to prevent carryover from sample to sample were developed.

- Microwave energy was precisely controlled using control software we developed to adjust magnetron power at one second intervals.

- Quantitative oxidation to pertechnetate is obtained within 30 seconds of heating with peroxydisulfate, and we determined that it is not necessary to completely oxidize the total organic carbon (TOC) in order to obtain quantitative Tc oxidation

- We determined that there is no significant losses of Tc analyte by volatilization under our conditions.

- The procedure was successful in overcoming the difficulties noted above and rapidly oxidizing 
the Tc in Hanford waste samples containing high organic content and a high proportion of nonpertechnetate species.

- A detailed manuscript on this sample pretreatment chemistry and instrumentation has been submitted to Analytical Chemistry and accepted with very favorable reviewer comments. [11]

Sample pretreatment and matrix modification procedures improve reliability in elemental and radiochemical analysis by reducing matrix effects and by ensuring compatibility of the sample matrix with subsequent separation and/or detection methods.[12-15] In the case of analytes with varying chemical and oxidation state speciation (e.g. As(III)/As(V); $\mathrm{Se}(\mathrm{IV}) / \mathrm{Se}(\mathrm{VI}) ; \mathrm{Cr}(\mathrm{III}) / \mathrm{Cr}(\mathrm{VI})$; $\mathrm{Tc}(\mathrm{IV}) / \mathrm{Tc}(\mathrm{VII})$ ), chemical reactions are typically required to convert the analyte to a desired chemical form or fixed oxidation state prior to total analyte measurements. [1, 8, 16-24]

Sample matrices associated with the aged nuclear waste process streams are comprised of caustic brine solutions where the speciation of ${ }^{99} \mathrm{Tc}$ is variable and dependent on the source of the waste.[2, 25] In some wastes with high organic content, up to $60-70 \%$ of total ${ }^{99} \mathrm{Tc}$ may be present as reduced nonpertechnetate species of unknown chemical composition (to be referred to as "nonpertechnetate").[2, $5,6,26]$ Recent studies indicate that nonpertechnetate may be associated with organic complexants such as gluconate.[26]

Previous studies on the radiochemical determination of the total ${ }^{99} \mathrm{Tc}$ in nuclear waste samples with high content of organic and nonpertechnetate species established that reliable and quantitative oxidation to pertechnetate represented a significant challenge, even in manual laboratory procedures. $[2,6]$ Oxidants such as $\mathrm{Cr}(\mathrm{VI}), \mathrm{H}_{2} \mathrm{O}_{2}$ and $\mathrm{Ce}(\mathrm{IV})$ added to acidified, heated samples were ineffective,[2] and procedures required many hours. Studies by Schroeder et al. identified peroxydisulfate as a promising oxidizing reagent in caustic samples, but reaction times were still 4 to 12 hours. $[5,6]$

Nevertheless, oxidation using peroxydisulfate was possible in matrices with stoichiometric excess of nitrite and organic carbon, which represent major sources of reducing capacity in the aged nuclear waste. Peroxydisulfate is a strong reagent that will oxidize both nitrite and organic compounds $\left(\mathrm{E}^{0}=2.01 \mathrm{~V}\right.$ for the $\mathrm{S}_{2} \mathrm{O}_{8}{ }^{2-} / \mathrm{SO}_{4}{ }^{2-}$ pair)). $[9,27]$ On further investigation, we found conditions where we could obtain successful oxidation of reduced technetium species using peroxydisulfate in diluted acidified samples within $\sim 5$ minutes at $100^{\circ} \mathrm{C}$. In caustic samples, however, we found that precipitates were formed that would have precluded reliable automation in a flow format. Based on these considerations we selected peroxydisulfate chemistry with prior sample acidification for investigation in an automated format.

We also developed a microwave-assisted method for performing this pretreatment. Because of the rapid, uniform and well controlled heat delivery, microwave-assisted sample preparation offers significant advantages in effectiveness, speed, and reproducibility relative to conventional sample treatment techniques based on conductive heating.[12, 13, 15]. Closed-vessel digestion formats are not ideally suited for sample treatment procedures that require sequential addition of multiple reagents or generate significant quantities of gaseous species.[14,28] Although microwave-assisted sample treatment at low temperatures and pressures have been reported in a continuous, flow-through regime using coiled tube flow reactors, which are functionally similar to closed-vessel reactors,[17, 21, 29-33] procedures that generate gaseous species result in the formation of gas segments in the tubing. This leads to uncontrolled and irreproducible flow behavior.[32,33]

In contrast, the open-vessel digestion format offers flexibility in the design of sample treatment procedures that require addition of multiple reagents and venting of gaseous products .[14, 34] However, the open-vessel format is more challenging for implementation in an automated flow format. There have been few reports on open vessel microwave-assisted sample pretreatment with automated or semi-automated fluid handling, and these have been concerned primarily with digestion of biological samples for metal determinations.[32, 33]

We developed an open-vessel microwave procedure using STAR 2 open-vessel microwave digestion system from CEM Corporation and replacing the standard digestion vessel with a vessel and 
vessel holder of our own design. This vessel, shown schematically in Figure 1a, consisted of a smallvolume concave-bottom reaction vessel modified with one line extending to the bottom center of the vessel for solution deliveries and sample retrieval. A second line was added as a vent for outgassing, and a holder was designed to position the vessel in the microwave cavity. Using a fluidic system of pumps and valves that we designed around this vessel, we obtained consistently reliable quantitative retrieval of the digested sample from the reaction vessel for subsequent analysis. This flow-cell design is well suited for automated processing of small samples, and represents an improvement in design relative to previously reported flow cells for automated open-vessel microwave digestions.[32]

Using this instrumentation, we developed an acidification procedure with gentle heating as a first digestion step. We determined a concentration of nitric acid that avoided the excessive foaming that occurred with concentrated nitric acid. We determined an amount of nitric acid that would neutralize the total base content, adjust the final acidity for subsequent separation (excess acidity interferes with pertechnetate retention in the subsequent separation) and dissolves the $\mathrm{Al}(\mathrm{OH})_{3}$ precipitate that formed as acidification began. (Caustic nuclear waste sample matrices have a high content of dissolved $\mathrm{Al}$ from 4$17 \mathrm{~g} / \mathrm{L}) \cdot[35]$

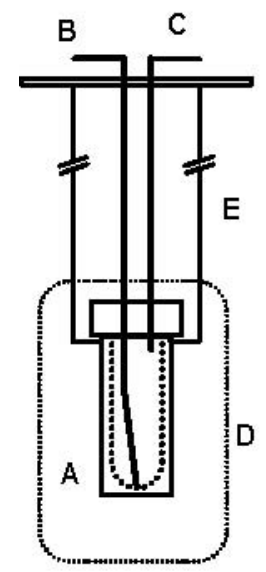

a)

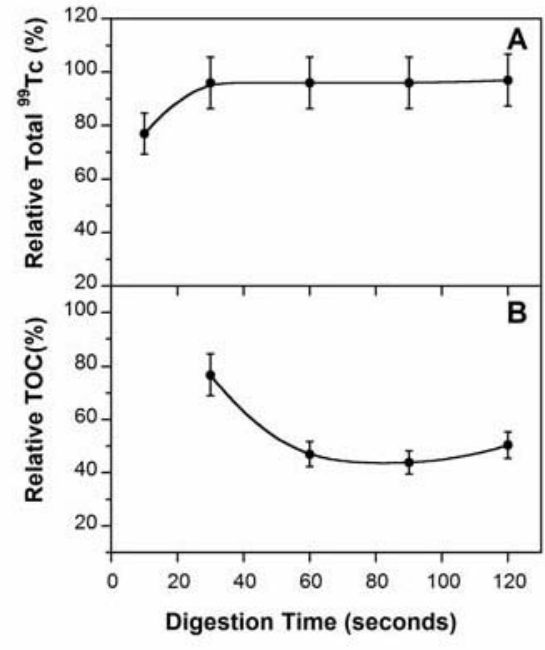

b)

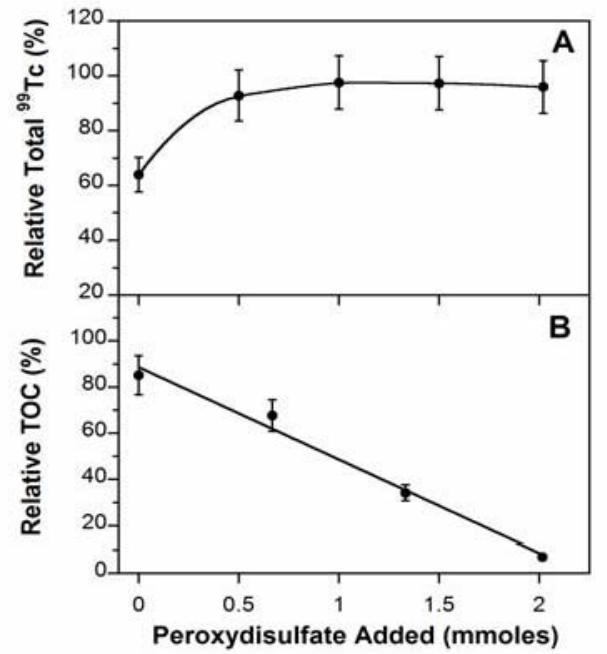

c)

Figure 1. a) Schematic diagram of the flow-through reaction vessel design for microwave assisted sample treatment. A, concave-bottom reaction vessel; B, sample/reagent delivery line; C, vent line; D, microwave cavity; E, reaction vessel holder. b) Plot of the relative total ${ }^{99} \mathrm{Tc}$ measurement (graph A) and the relative TOC content in digested samples (graph B) as a function of digestion time. Amount of peroxydisulfate added to the sample is 1.4 mmoles in both cases. and c) Plot of the relative total ${ }^{99} \mathrm{Tc}$ measurement (radiochemical analysis/ ICPMS analysis) (graph A) and the relative TOC content in the digested sample (graph B) as a function of peroxydisulfate mole quantity added to the acidified nuclear waste sample. Digestion times are 60 and 90 seconds for the relative total ${ }^{99} \mathrm{Tc}$ and relative TOC results, respectively.

We studied the oxidation of reduced technetium species and organic carbon in detail, as shown in Figures $1 \mathrm{~b}$ and $1 \mathrm{c}$, and developed an automated procedure for oxidation using peroxydisulfate as a second digestion step. The percentage of the total Tc in the sample that is found by radiochemical analysis of the digested samples is plotted in Figure $1 \mathrm{~b}$ (graph A) as a function of the quantity of oxidant 
added to the sample, where the total Tc was determined by ICPMS. These relative total ${ }^{99} \mathrm{Tc}$ results indicate that addition of peroxydisulfate reagent in excess of 0.5 mmoles $(0.7$ mmoles per $1 \mathrm{~mL}$ of the nuclear waste sample) results in close agreement between the pertechnetate-specific radiochemical analysis procedure and speciation-independent ICPMS techniques.

To provide an excess for reliability, we selected $0.7 \mathrm{~mL}$ of $2 \mathrm{M} \mathrm{Na}_{2} \mathrm{~S}_{2} \mathrm{O}_{8}$ (1.9 mmoles of peroxydisulfate per $1 \mathrm{~mL}$ of the nuclear waste sample) for use in automated sample treatment procedure. The relative total ${ }^{99} \mathrm{Tc}$, obtained as a function of the length of the second digestion is shown in Figure 1c (graph A). Microwave-assisted Tc oxidation is quite rapid, providing quantitative results after $\sim 30$ seconds under our selected conditions ( $5 \%$ continuous magnetron power level; gentle boiling under continuous gas agitation).

TOC analyses were performed to determine the percent TOC remaining as the function of the digestion time, as shown in Figure 1b, graph $\mathrm{B}$, using $0.7 \mathrm{~mL}$ of $2 \mathrm{M} \mathrm{Na}_{2} \mathrm{~S}_{2} \mathrm{O}_{8}$. No further reduction in TOC content after 90 seconds of digestion is likely indicative of complete consumption of the oxidizing reagent. Quantitative oxidation of the nonpertechnetate species was obtained with a significant fraction of the TOC still present in the sample; complete destruction of the TOC is not a prerequisite for reliable control of the ${ }^{99} \mathrm{Tc}$ speciation in aged nuclear waste samples.

Graph B in Figure 1c shows that the extent of the TOC oxidation is determined by the amount of oxidant added to the sample and increases linearly with an increase of the amount of peroxydisulfate. For the sample matrices and digestion conditions used in this study, 1.4 moles of $\mathrm{S}_{2} \mathrm{O}_{8}{ }^{2-}$ was required to oxidize 1 mole of organic carbon to $\mathrm{CO}_{2}$ in acidified aged nuclear waste sample.

From these and additional studies not described here, we developed a successful approach in which we integrated matrix modification and speciation control chemistry, an open-vessel microwave digestion apparatus, a fluidic system, and a detailed automated protocol.

\section{Approach}

\section{Separation Chemistry for Total Tc.}

- Investigate effectiveness of the uptake and chromatographic behavior of materials for the rapid analytical separation of ${ }^{99} \mathrm{Tc}$ (VII) from interfering radionuclides in high-salt digested (oxidized) sample

- Investigate sample loading and column wash sequences necessary for reliable removal of interfering radionuclides and high analyte recoveries using spiked simulants and actual wastes via fraction collection combined with nuclear spectroscopic and ICP MS analysis of the collected fractions.

- Develop, optimize, and rigorously test automated separation procedures using spiked simulants and actual nuclear waste samples in order to verify effectiveness of the analytical separation and column longevities in varying sample matrices (Hanford waste Envelopes A, B, and C).

\section{Successes}

- Several sorbent materials (TEVA Resin, Superlig 639, MP-1M) were evaluated and compared

- Although the materials initially proposed (TEVA, Superlig 639) were not entirely satisfactory, the strongly basic anion exchange sorbent material (MP-1M) was found that met all the requirements for uptake, selective separations, adequate elution, and which demonstrated superior column life

- Reliable separation was possible at high flow rates (up to $7.5 \mathrm{~mL} / \mathrm{min}$ ) as required for the development of rapid analytical procedures.

- An isotope ${ }^{121 \mathrm{~m}} \mathrm{Sn}$, previously undetermined in the aged waste matrices, was identified by us as a significant interferent that can be present in aged waste at activity levels exceeding those of ${ }^{99} \mathrm{Tc}$, especially in waste with a high content of organics.

- A comprehensive separation procedure was developed that successfully addressed the challenge of separating anionic radionuclides (isotopes of $\mathrm{Sn}, \mathrm{Sb}$, and $\mathrm{Ru}$ ) which were found to interfere 
with ${ }^{99} \mathrm{Tc}$ analysis in aged wastes. The effectiveness of the separation procedure was verified in the numerous experiments with actual Hanford nuclear waste samples.

- The separation sequence was successfully implemented in the automated format

Analytical separations are required prior to radiometric detection for the reasons cited in the introductory sections. In the Phase 1 proposal, we identified two separation chemistries for the development of rapid automated ${ }^{99} \mathrm{Tc}$ separations: extraction chromatographic material (Eichrom TEVA Resin) and Tc(VII) specific solid phase extraction material (IBC Superlig 639). After careful investigations, each of these was found unsatisfactory. The TEVA resin was not suitable for repetitive column reuse under pressure and the SuperLig 639 released the analyte too slowly for rapid analyses. We succeeded, however, in identifying a macroreticular strongly basic anion exchange material (MP-1M) that provided effective separations, adequate elution kinetics for rapid procedures, and extended column lifetimes under elevated pressures. This material provided excellent selectivity for the uptake of ${ }^{99} \mathrm{Tc}$ relative to major radioactive constituents $\left({ }^{137} \mathrm{Cs},{ }^{90} \mathrm{Sr} /{ }^{90} \mathrm{Y}, \mathrm{U}, \mathrm{Pu}, \mathrm{Am}\right)$ in dilute nitric acid media. A comprehensive separation procedure was developed that comprises a sequence of multiple acidic, hydroxide and complexant column wash steps for reliable separation of ${ }^{99} \mathrm{Tc}$ from interferences using anion exchange sorbent materials.

${ }^{99} \mathrm{Tc}$ separation using extraction chromatographic sorbents. Based on previous literature data and our past experience, we initially considered TEVA resin to be the preferred separation chemistry. This extraction chromatographic material, based on the long-chain quaternary ammonium salt extractant (Aliquat 336) immobilized in an inert polymeric support, is now commonly used in radiochemical analysis of ${ }^{99} \mathrm{Tc}$. Our own initial batch uptake and column experiments, confirmed its separation effectiveness, with $\mathrm{K}_{d}$ values of $\sim 1200$ and $1600 \mathrm{ml} / \mathrm{g}$ for ${ }^{99}$ Tc uptake in acidified AN-105 and AW-101 nuclear wastes simulant matrices, respectively. The sharp drop in retention with increasing acid concentration provided rapid ${ }^{99} \mathrm{Tc}$ elution with sharp elution profiles.

Nevertheless, column reuse more than 50 times was problematic, with reduced separation recoveries and shifts in the position of ${ }^{99} \mathrm{Tc}$ elution peak upon continuous column reuse. We attribute this to the loss of the stationary organic extractant phase, which represents a generic challenge for the implementation of extraction chromatographic materials in automated radiochemical analysis systems for long-term monitoring.

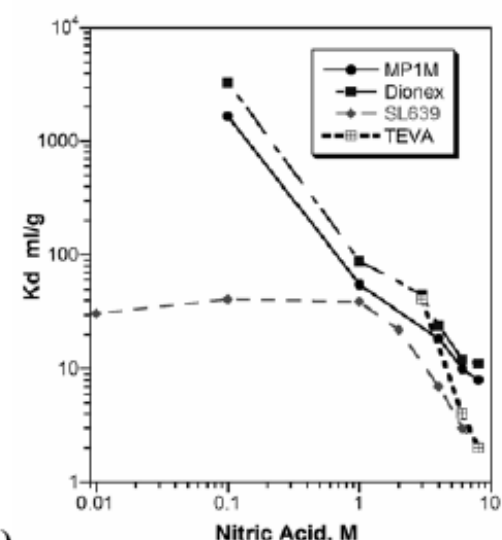

a)
Nitric Acid, M

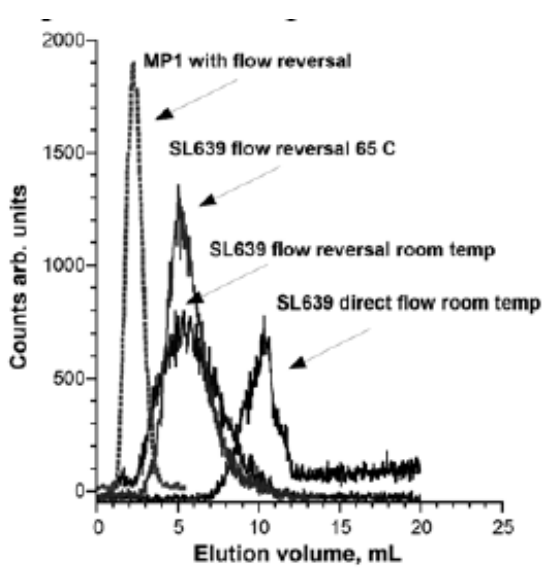

b)

Figure 2. a) Uptake of the ${ }^{99} \mathrm{Tc}$ (VII) from nitric acid media using candidate sorbent materials. b) ${ }^{99}$ Tc elution behavior from the SuperLig 639 column and strongly basic anion exchange (MP1) column. 
${ }^{99} \mathrm{Tc}$ separation using Tc-selective solid phase extraction material. Superlig 639 material comprises a proprietary pertechnetate-selective ligand covalently attached to a polymeric bead support. $\mathrm{Tc}$ uptake was determined as a function of $\mathrm{Na}+$ concentration and acid concentration. A low $\mathrm{K}_{\mathrm{d}}$ of $3 \mathrm{ml} / \mathrm{g}$ was found in DI water, increasing to 1000 in $1 \mathrm{M} \mathrm{Na}+$. The ${ }^{99} \mathrm{Tc}$ uptake as a function of nitric acid concentration is shown in Figure 2a. In separate experiments we also determined the ${ }^{99} \mathrm{Tc}$ uptake in acidified digested sample matrix after microwave assisted sample treatment $\left(\mathrm{K}_{\mathrm{d}}=63 \mathrm{~mL} / \mathrm{g}\right)$. We observed reduced Tc uptake in strong acid and resin discoloration, suggesting resin deterioration.

Column flow experiments with fraction collection and off-line analysis using actual Hanford Envelope C waste samples (Tank AN-107 and AN-102) indicated that Superlig 639 material provided excellent selectivity for ${ }^{99} \mathrm{Tc}$ (VII) over other radionuclide constituents of the aged nuclear waste samples. Nevertheless, column experiments using on-line detection indicated slow elution kinetics and broad peaks, as shown in Figure 2b. Broader elution peaks are disadvantageous as they lead to reduction in detection limits using on-line radiometric detection.

${ }^{99} \mathrm{Tc}$ separation using anion exchange solid phase extraction material. The issues identified above prompted us to investigate alternative separation materials. Strongly basic anion exchange materials are comprised of quaternary ammonium functionality covalently attached to the polymeric supports. The uptake data for macroreticular material MP-1 and pellicular Dionex material are shown in Figure 2a. In addition, batch contact studies indicated that both materials exhibited good affinity for ${ }^{99} \mathrm{Tc}$ (VII) from the acidified oxidized nuclear waste matrices $\left(\mathrm{K}_{\mathrm{d}} \sim 100 \mathrm{ml} / \mathrm{g}\right)$. Flow testing with on-line radiometric detection indicated that MP-1 material exhibited better elution kinetics and sharper elution peaks using $8 \mathrm{M}$ nitric acid.

Strongly basic anion exchange materials exhibit good selectivity towards ${ }^{99} \mathrm{Tc}(\mathrm{VII})$ over other radionuclides commonly present in the nuclear waste. An initial separation procedure with uptake in strong acid and elution using $0.2 \mathrm{M}$ nitric acid and $0.2 \mathrm{M}$ nitric acid-0.2 $\mathrm{M}$ oxalic acid enabled good separation and accurate ${ }^{99} \mathrm{Tc}$ quantification in the low organic waste matrices containing radioactive ${ }^{90} \mathrm{Sr} /{ }^{90} \mathrm{Y}$ and ${ }^{137} \mathrm{Cs}$. Nevertheless, subsequent analysis of the high organic waste Envelope $\mathrm{C}$ matrices resulted in a positive bias, indicating presence of an interfering radionuclide species co-eluting with ${ }^{99} \mathrm{Tc}$. An extensive effort was made to identify this unexpected interference. Analysis of the Tc fraction using ICP-MS indicated significant quantities of Sn isotopes that are produced in fission reactions. Further analysis using Low Energy Photon Spectroscopy (LEPS) revealed the presence of X-rays characteristic to the decay of isotope of ${ }^{121 \mathrm{~m}} \mathrm{Sn}$. In addition, this isotope is a pure beta-emitter with a maximum beta energy similar to that of ${ }^{99} \mathrm{Tc}$. It has not been previously detected or quantified in the Hanford aged nuclear waste samples. 


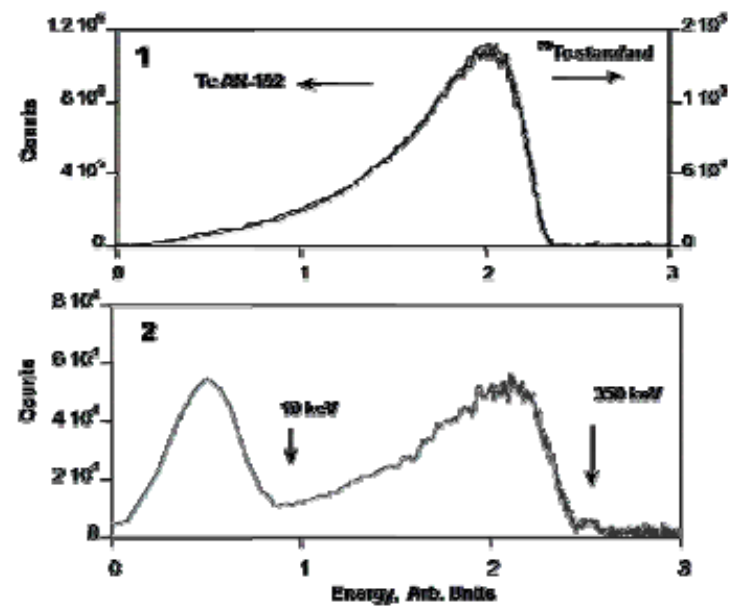

a)

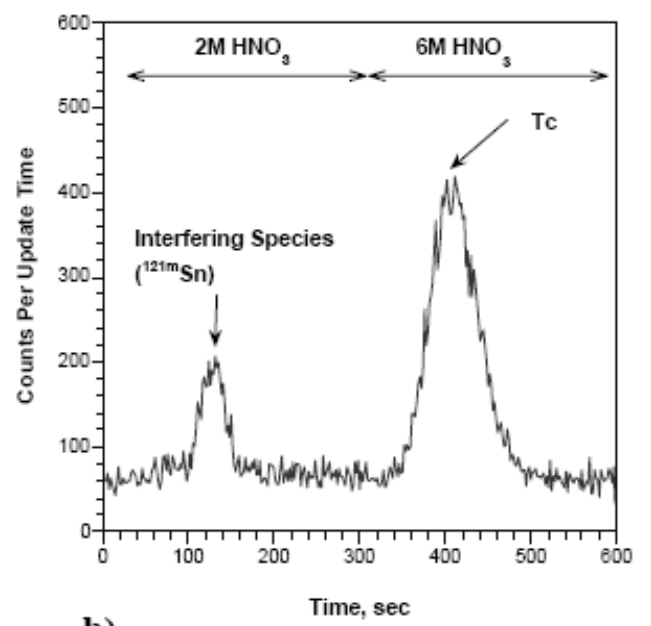

b)

Figure 3. a) Liquid scintillation spectra of the ${ }^{99} \mathrm{Tc}$ standard and Tc fraction separated from high-organic Hanford tank using comprehensive separation sequence (1), and liquid scintillation spectrum of ${ }^{121 \mathrm{~m}} \mathrm{Sn}$ found to interfere with the ${ }^{99} \mathrm{Tc}$ analysis using initial separation procedure (2). b) Separation of ${ }^{121 \mathrm{~m}} \mathrm{Sn}$ interferents using $2 \mathrm{M}$ nitric acid wash.

Additional experimentation revealed that incorporation of medium concentration nitric acid wash ( $2 \mathrm{M}$ nitric acid) enables removal of $\mathrm{Sn}$, while Tc remains on the column. This separation is illustrated in Figure $3 \mathrm{~b}$. This revised separation procedure removed the positive bias found previously.

These results prompted us to determine which radionuclides could be present in the aged nuclear waste samples at levels comparable to that of ${ }^{99} \mathrm{Tc}$. The abundance of fission products in aged wastes was calculated based on their fission yields and radioactive half-lives. Additional criteria in this analysis, was the tendency to form anionic species that may be retained on the anion exchange material. Our calculations indicated that ${ }^{121 \mathrm{~m}} \mathrm{Sn}$ can be present in the aged waste at activity levels exceeding those of ${ }^{99} \mathrm{Tc}$. Additional identified radionuclides of concern that could be present at activity levels comparable with that of Tc were isotopes $\mathrm{Sb}, \mathrm{Ru}$ and $\mathrm{Ru} / \mathrm{Rh}$.

We set out to develop a comprehensive separation procedure that would enable complete and reliable separation of ${ }^{99} \mathrm{Tc}$ in all Hanford waste envelopes with the particular emphasis on high organic samples. Using fraction collection, ICP MS, gamma and X-ray spectroscopy for analysis of collected fractions, we developed a comprehensive separation procedure that consisted of wash sequences using 0.2 $\mathrm{M} \mathrm{HNO}_{3}, 6 \mathrm{~mL}$ of $1 \mathrm{M} \mathrm{NaOH}, 6 \mathrm{~mL}$ of $0.2 \mathrm{M} \mathrm{HNO}_{3}-0.5 \mathrm{M} \mathrm{H}_{2} \mathrm{C}_{2} \mathrm{O}_{4}$, and $5 \mathrm{~mL}$ of $2 \mathrm{M} \mathrm{HNO}_{3}$. In extensive testing using Envelope A, B, and $\mathrm{C}$ samples this procedure was determined to enable reliable separation of ${ }^{99} \mathrm{Tc}$ (VII) from ${ }^{121 \mathrm{~m}} \mathrm{Sn},{ }^{126} \mathrm{Sb}$, and ${ }^{106} \mathrm{Ru} /{ }^{106} \mathrm{Rh}$ in the analysis of aged nuclear waste. The comprehensive procedure enabled reliable and accurate quantification of ${ }^{99} \mathrm{Tc}$ in all types of Hanford waste.

These results indicate that systematic scientific development is essential in order to address previously undocumented challenges associated with actual waste samples and leads to new knowledge. It is interesting to note that ${ }^{121 \mathrm{~m}} \mathrm{Sn}$ has not been measured in tanks prior to this work. In addition tank waste characterization reports indicate that up to $30 \%$ of tank waste activity is sometimes attributed to unidentified beta emitters. 


\section{Approach}

Integration, Automation and Quantification.

- Sample preparation, separation, and detection were integrated into a complete instrument and fully automated.

- Performance was rigorously evaluated against standards and waste samples, and unexpected interference issues were investigated and resolved.

\section{Successes}

- Flow-through solid scintillation detection provides adequate sensitivity to meet required detection limits.

- Automated calibration approach using standard addition technique was developed and verified using simulants and actual wastes samples.

- The instrument was extensively tested with all envelopes of Hanford waste using LAW simulants and actual AN-107, AN-102, AZ-101, AZ-102, and AP-104 Tc decontaminated LAW matrices.

- Automated unattended operation for over 40 hours continuous operation have been demonstrated

- The analyzer meets or exceeds all Hanford-specified requirements, with a total analysis time of 12.6 minutes per sample (see below)

- Tc analyzer development is complete.

The microwave-assisted sample digestion and subsequent analytical separation were integrated with a solid-scintillator radiometric detector and fully automated. The detection module was configured with the Beta-Ram 2B ${ }^{\circledR}$ flow-through scintillation detector (IN/US Systems, Inc. Tampa, FL). A solid scintillator cell (Li glass) flow cell (1 mL volume) provided good detection efficiency $(\sim 65 \%)$ which is comparable to that of liquid scintillation detection. Our studies indicated excellent stability of the glass scintillator in the $8 \mathrm{M}$ nitric acid used for ${ }^{99} \mathrm{Tc}$ elution. Detection is performed with flowing, not stopped flow, counting.

The instrument is shown in schematic and photographic form in Figure 4. Details will not be provided here. Software was developed to process the detector data, using data smoothing and peak search routines to improve quantification at low signal to noise. A smart standard addition method was incorporated into the automated protocol for reliable quantification. After running the sample once, the optimum amount of standard for addition is calculated and spiked during the sample acidification step of the next run. . The difference in the responses between two measurements is used to calculate instrument calibration parameter or overall analysis efficiency. In order to provide statistically valid standard addition with minimal error, the instrument automatically calculates the amount of standard to be added, so that the signal derived from the spiked sample exceeds that of an unspiked sample by a factor of three. Standard addition calibrates the instrument, verifies general instrument performance, and deals with variable sample matrices. 


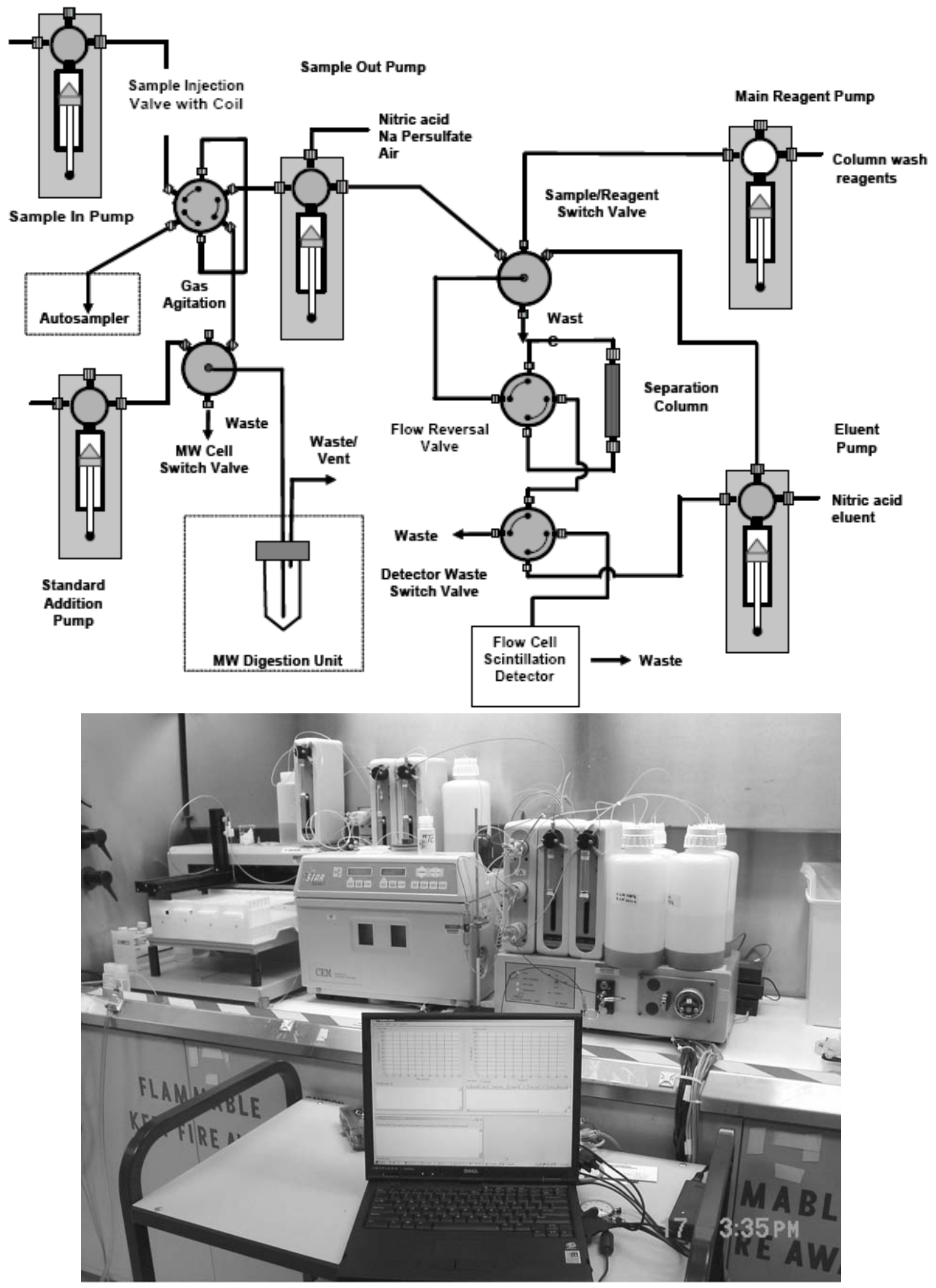

Figure 4. Schematic diagram and photographic image of the fully automated Tc monitor. 
The fully integrated and automated analyzer meets or exceeds Hanford-specified operational requirements. The instrument has the following performance characteristics:

- Detection limit of $6.36 \times 10^{-7} \mathrm{Ci} / \mathrm{L}$ of ${ }^{99} \mathrm{Tc}$ in LAW with $5 \mathrm{M} \mathrm{Na}{ }^{+}$concentration using $0.5 \mathrm{~mL}$ sample volume. (Performance requirement is $1.0 \times 10^{-6} \mathrm{Ci} / \mathrm{L}$ of $\left.{ }^{99} \mathrm{Tc}\right)$.)

- Rapid analysis time: analysis time of 12.6 minutes per sample. (Performance requirement is 1520 minutes per sample.)

- Analysis precision of better than $10 \% \mathrm{RSD}$ at concentration above the quantification limit (10 times the detection limit or $1.0 \times 10^{-5} \mathrm{Ci} / \mathrm{L}$ of ${ }^{99} \mathrm{Tc}$ ). (Performance requirement is $10 \% \mathrm{RSD}$.)

- Analysis accuracy is better than 15\% for the analysis of AN-102, AN-107, AZ-101, AZ-102, AP104 LAW matrices at concentrations above the quantification limit (10 times the detection limit or $1.0 \times 10^{-5} \mathrm{Ci} / \mathrm{L}$ of $\left.{ }^{99} \mathrm{Tc}\right)$. (Performance requirement is $15 \%$ accuracy.)

After a comprehensive and competitive review, the automated radiochemical instrument was selected for the use in the Hanford WTP with the contractor making provisions for the development of commercial analyzer.[36] This represents a significant achievement in conducting cutting edge scientific investigation, while addressing the real need at the DOE site with the simultaneous transfer of the knowledge to the contractor. This success would have not been possible without extensive systematic investigation of the scientific and challenging issues related to the total ${ }^{99} \mathrm{Tc}$ analysis.

\section{Radiometric Detection Methodologies}

\section{Introduction}

The development of functional radiochemical analyzers capable of meeting analysis time and detection limit requirements necessitates improvement in flow-through radiometric detectors. Improved scintillation detection methodologies, light detection techniques and detector configurations are required for quantification of beta emitting ${ }^{99} \mathrm{Tc}$ and ${ }^{90} \mathrm{Sr}$ in the process analyzers using flow-through radiometric detectors. In addition, the development of novel detection methodologies based on diode and thin film scintillation detectors is necessary to enable rapid and sensitive analysis of alpha emitters/ Digital signal processing offers the potential to improve the sensitivity of scintillation and solid state detectors

Both diode detectors and thin films scintillators were investigated as a means to detect alpha emitters in thick liquid sources for process monitoring applications. Diode detection can be used for total alpha analysis and provide alpha energy information to discriminate among individual radionuclides. Scintillation can be used in total alpha analysis only. In addition, several instrumental aspects of detection were investigated including digital signal processing for pulse shape discrimination, light detection devices, and flow cell design.

Solid State Detectors for Quantification of Alpha-emitters in Liquids Approach

- The detection of alpha emitters in liquid samples using diode detectors was investigated.

- Sample geometries with the detector in direct contact with the liquid and with small separations between the liquid and detector surface were examined, and models were developed for the effects of sample geometry.

- Total alpha measurements were made, as well as alpha energy spectra with spectral deconvolution to determine individual isotopes in mixtures.

- Sample/detector geometry effects, sensitivity, and interference issues were investigated in detail 


\section{Successes}

- Although conventional silicon diode alpha detectors were unreliable in this application, modern passivated ion implanted (PIPS) detectors were found that are robust and practical for operation in contact with liquids or with a small spatial separation.

- Characteristic alpha energy spectrum information was successfully extracted from these measurements, even though this measurement configuration corresponds to the analysis of infinitely thick alpha sources

- Although detection efficiencies are low, and sensitivity varies with the alpha energy from the dominant radionuclides, we found that total alpha analysis using diode detectors is feasible to meet detection limit requirements in process analysis where sample composition is generally known and consistent.

- Accurate analysis of total alpha activity was demonstrated for the actual Hanford and Savannah River Site samples

- We developed spectral deconvolution algorithms for the direct analysis of liquid samples and demonstrated it on a five component mixture.

- Investigated beta/gamma interference issues

- Developed calibration strategies for direct analysis of liquid samples

Conventionally, diode detectors can be used for alpha energy analysis, provided that the sample is thin and the gap between the sample is either gas or vacuum. We developed ways to use diode detectors for total alpha analysis, as required for process analysis, on liquid samples. In addition, we developed methods to obtain alpha energy spectral information from thick liquid sources. Modern PIPS diodes were used.

As a practical matter, we determined that the measurements could be made without the detector surface in direct contact with potentially corrosive solutions, using either an air gap or a thin solid barrier (mylar film in our experiments). The effects of geometry were measured and successfully modeled.

A)

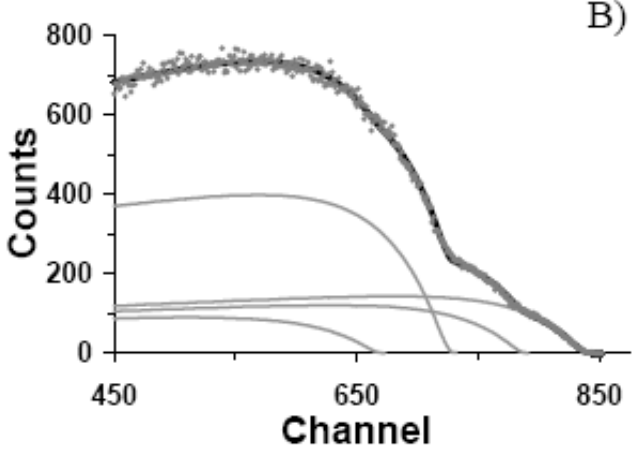

B)

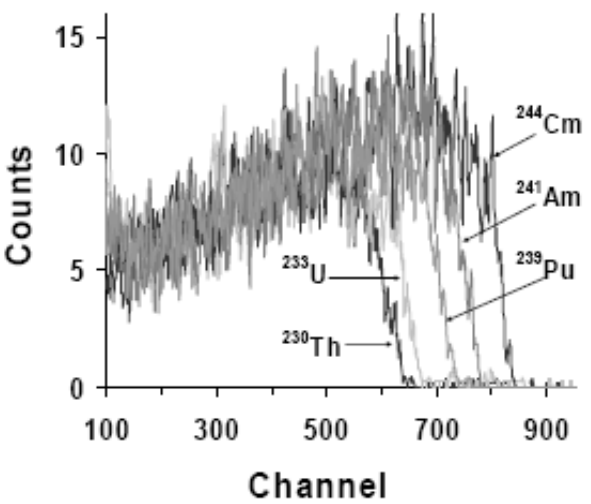

Figure 5. A) Spectral responses of different alpha emitter obtained using direct analysis of liquid samples using diode detector at a standoff distance of $0.5 \mathrm{~cm}$. B. Spectral deconvolution and individual isotopic analysis in the direct analysis of a liquid sample containing a mixture of ${ }^{230} \mathrm{Th},{ }^{233} \mathrm{U},{ }^{239} \mathrm{Pu},{ }^{241} \mathrm{Am}$, and ${ }^{244} \mathrm{Cm}$.

In contrast to thin sources, the spectral responses in our experiments consisted of well-defined high energy leading edges with tailing extending throughout the low energy region (see Figure 5). Thus mixtures have extensive overlap rather than separate peaks, and the position of the leading edge is characteristic of the alpha particle energy. The energy spectra for five individual alpha-emitters $\left({ }^{230} \mathrm{Th}\right.$, 
$\mathrm{E} \alpha=4.688 \mathrm{MeV} ;{ }^{233} \mathrm{U}, \mathrm{E} \alpha=4.821 \mathrm{MeV} ;{ }^{239} \mathrm{Pu}, \mathrm{E} \alpha=5.157 \mathrm{MeV} ;{ }^{241} \mathrm{Am}, \mathrm{E} \alpha=5.486 \mathrm{MeV} ;{ }^{244} \mathrm{Cm} \mathrm{E} \alpha=5.806$ $\mathrm{MeV}$ ) in liquid samples obtained using PIPS diode at a stand-off distance of $0.5 \mathrm{~cm}$ are compared in Figure 5, plot A. The high energy leading edge of the liquid sample spectra were found to scale linearly with the alpha particle energy. We also determined that the high energy spectral edges of liquid sources align closely with those of electroplated thin sources measured at equivalent stand-off distances. Note that the high energy edges of the ${ }^{239} \mathrm{Pu}$ and ${ }^{241} \mathrm{Am}$ spectra in Figure 6 are well resolved (alpha particle energy difference is $0.329 \mathrm{MeV}$ ). Hence, alpha energy (isotopic) information can be obtained from the liquid sample, given sufficient signal to noise. The energy resolution and measurement sensitivity is enhanced when diode detectors are placed in direct contact with solution.

The most sensitive alpha activity measurements can be obtained by integrating counts across the full spectral range (200-900 channels, or 0.5-6 MeV), which extends above the low energy noise region (0-150 channels). Nevertheless, we determined that the use of the higher energy window (550-900 channels) is typically required in order to eliminate interfering signals from high levels of beta and gamma emitters which are highly abundant in the aged nuclear waste. For the alpha emitting radionuclides in the energy range of $\sim 5.5 \mathrm{MeV}$ the observed counting efficiencies (expressed as counts per second per Bq/mL of sample activity) are on the order of $0.1 \%$. Relatively low counting efficiencies observed in direct analysis of alpha-emitters in liquid samples were anticipated due to the short range of alpha particles in liquids. Nevertheless, counting efficiencies are sufficient to enable rapid process measurements at required detection levels. For example, the minimum detectable ${ }^{241}$ Am activity level for direct analysis of liquids sample was determined to be $23 \mathrm{~Bq} / \mathrm{mL}$ for 10 minute counting interval. These detection limits are sufficient for typical analyses in support of process monitoring. Further reduction in detection limit can achieved using longer counting times or using sample preconcentration.

Linear calibration plots were successfully obtained for direct analysis of alpha-emitting radionuclides in liquids. However, unlike thin sources, the slopes of calibration plots were different for radionuclides with varying alpha energy. This arises from the escape dynamics of the alpha particles from thick liquid sources. Empirically, the relative portion of alpha particles escaping from the thick liquid source increases with particle energy and is not a function of the diode detection, which is thick enough to capture all alpha energy. Additionally, given the tailing in the lower energy range, the portion of alpha particles detected above the low energy (beta) noise increases with the alpha particle energy.

As a result, total alpha analysis of mixtures is potentially problematic; to obtain quantitative results, efficiency calibration must be carried out using a standard with the alpha particle energy distribution similar to that of the sample matrices to be analyzed. In general, this issue is of less significance for the process monitoring analysis where waste composition is known and consistent. For example, significant portion of total alpha activity in Hanford is largely due to ${ }^{241} \mathrm{Am}$ (up to $50 \%$ ). Using ${ }^{241} \mathrm{Am}$ as a calibration standard we demonstrated feasibility of accurate analysis of actual nuclear waste samples with the total alpha results obtained by diode analysis being in close agreement with the reported laboratory analysis values.

We further investigated the possibility of individual isotopic analysis, taking advantage of the energy resolution capabilities of the diode detectors and characteristic shapes of the spectral responses (Figure 5). A number of mathematical relationships were evaluated for the modeling and assay of alpha spectra from diffuse homogeneous "infinitely" thick sources. The Bragg equation, based upon fundamental principles, describes the energy deposition of ejected alpha particles as they travel through material. Unfortunately, this multivarient differential equation does not have closed form solution for an alpha energy spectra from infinitely thick sources. The most successful model which provided spectral deconvolution was found to be a combination of linear, exponential and Gaussian functions used to describe observed energy responses as function of energy:

$$
f(x)=A \varepsilon[g(x)+h(x)+j(x)]
$$

where $f(x)$ is the calculated spectral response, A is the total number of counts in the spectra, $\mathrm{x}$ is the channel number, and $\varepsilon$ counting efficiency for the radionuclide. This model was used to provide accurate 
description of the individual alpha particle spectra for direct analysis of liquid samples. Moreover, we found that complex spectral responses of for samples containing multiple alpha-emitters could also be accurately described by this model using a summation of the individual models for each radionuclide. The feasibility of individual isotopic analysis of the liquid sample containing ${ }^{241} \mathrm{Am}$ ( $15 \%$ total alpha activity), ${ }^{239} \mathrm{Pu}\left(50 \%\right.$ activity), ${ }^{244} \mathrm{Cm}$ (20\% activity) and ${ }^{233} \mathrm{U}$ (15\% activity) is illustrated in Figure 5B. Using our model individual isotope quantification with the accuracy of $2 \%$ was possible.

In summary direct analysis of liquid samples using diode detectors is a viable analytical methodology for determination of alpha-emitting radionuclides in process streams. The use of diode detectors in direct liquid measurement provides energy information that can be used for identification of the individual alpha-emitters. Further improvement in selectivity, sensitivity, and robustness can be achieved through appropriate design of fluidic interface, development of digital signal processing and spectral deconvolution techniques.

\section{Total Alpha Activity Measurements in Liquids Using Thin Film Scintillators Approach}

- $\quad$ Ag-doped $\mathrm{ZnS}$, i.e. $\mathrm{ZnS}(\mathrm{Ag})$, thin scintillator layer coupled to a PMT detector was evaluated for the purpose of total alpha analysis in liquid samples as an alternative to diode detectors

- Measurements were carried out by placing a scintillator disc close to the liquid sample surface.

- Energy discrimination settings were selected that minimize interferences from beta emitters

\section{Successes}

- Total alpha analysis using scintillation detection was demonstrated for detection of ${ }^{233} \mathrm{U}$ in waste simulant matrices containing ${ }^{90} \mathrm{Sr}$

- Experimental detection efficiencies for analysis of infinitely thick sources were compared with the model values and were in satisfactory agreement

We conducted experiments on the use of scintillation detection as a potential alternative to diode detectors for direct analysis of total alpha activity in liquid samples. A ZnS (Ag) scintillator layer was coupled to a PMT detector and used in a measurement configuration similar to that described for the use of diode detectors. Because of the fundamental limitation of scintillation detection this approach does not provide energy resolution and does not discriminate between the individual isotopes. Nevertheless, in contrast to diode detection, detection efficiency was not found to be strongly dependent on the alpha particle energy. In this manner, scintillation detection may be advantageous for total alpha analysis.

ZnS scintillator exhibits much higher sensitivity for detection of alpha particles relative to beta and gamma particles and energy discrimination was successfully reduce contribution from non alpha emitters. Pulse height spectra for ${ }^{233} \mathrm{U}$ and ${ }^{90} \mathrm{Sr} /{ }^{90} \mathrm{Y}$ sources were acquired and used to set the energy discrimination threshold for elimination of beta interferences. Continuum pulse height spectra for ${ }^{233} \mathrm{U}$ was observed, as expected, in this thick liquid source geometry. Experimental detection efficiencies for ${ }^{233} \mathrm{U}$ and ${ }^{237} \mathrm{~Np}$ were determined to be $\sim 17 \%$ assuming detection from the sample depth of $35 \mu \mathrm{m}$. This value is in close agreement with the model values.

Further studies are required to determine optimal measurement configuration and to compare and contrast scintillation and diode detection for the purpose of direct total alpha analysis in liquid samples. In general this approach appears promising for total alpha energy measurements in process streams and may address the issues identified for diode detectors. 


\section{Approach}

\section{Advanced Photodetectors for Scintillation Applications}

- Photon detectors other than photomultiplier tubes (PMTs) were investigated for detection of scintillation light

- Compared to PMT detectors, solid state photon detectors offer higher quantum efficiencies, smaller size and reduced power consumption

\section{Successes}

- A flow detection system using two silicon PIN-photodiodes (PD) operated in coincidence was developed and demonstrated for detection of alpha and beta activities in liquids

- Digital signal processing of the PD was demonstrated for discrimination of alpha and beta events

- Characteristics of the photodiode light detectors were compared with the PMT

Conventionally, PMT detectors are used for detection of the scintillation light in flow-through and static scintillation detectors. Recently, solid state diode detectors have been developed for photon counting and detection applications. Compared to PMT, solid state detectors can potentially offer higher quantum efficiencies for better energy resolution, smaller physical size, lower power consumption and more rugged designs. In addition, semiconductor detectors have wider spectral range and can be coupled to scintillators with emission wavelengths greater than $500 \mathrm{~nm}$. Nevertheless, because the PD detectors do not provide intrinsic gain, electronic noise becomes a major consideration when using PD for light detection.

We developed a flow-cell detector (shown in Figure 6) utilizing a flow cell packed with microencapsulated granular CsI:Tl scintillator and using silicon PIN-photodiodes (PD) for detection of scintillating light. Signals from the PDs were processed by charge sensitive preamplifiers and shaping amplifiers then digitized by a GaGe CompuScope 8012A/PCI 12-bit dual channel 50-MHz digital oscilloscope card residing in a personal computer. The digitized signal was processed by a LabVIEWbased data acquisition program for pulse height and pulse shape analyses in conjunction with a softwarerealized coincidence mode with a resolving time of $800 \mathrm{~ns}$.

The detector system was used for simultaneous detection of alpha and beta radiation in liquids. By setting an appropriate region of interest (ROI) for alpha events in a dual parameter histogram, the spillover of beta events into alpha ROI was less than 3.9\% as shown in Figure 6. The initial detection efficiency for ${ }^{233} \mathrm{U}$ was $19.5 \%$, which was lower than the PMT system in part due to the thicker encapsulation layers on the scintillator. Despite the use of coincidence counting and careful optimization of the pulse shaping time, we observed that the background count rate of the PD system was higher and the spillover greater than the PMT system. These factors are attributed to electronic noise. Because of the smaller physical size of the PD, the flow-cell volume was smaller $(0.075 \mathrm{~mL})$ than that of the PMT system $(0.15 \mathrm{~mL})$ The alpha minimum detectable concentration of a CsI:Tl flow-cell was calculated to be 12.4 $\mathrm{Bq} \mathrm{mL}^{-1}$ and $2.5 \mathrm{~Bq} \mathrm{~mL}^{-1}$ for the PD and PMT systems, respectively, for a 120 -s count time.

Initial results indicate that PD photon detectors do not offer immediate advantage to the PMT in designing flow-through radiometric detectors. Additional work remains to be done using avalanche photodiodes and hybrid PMT to determine full potential of solid state light detectors as an alternative to the PMT in flow-through scintillation detection for process monitoring. Mitigation of the electronic noise remains to be one of the key issues with these detectors. 

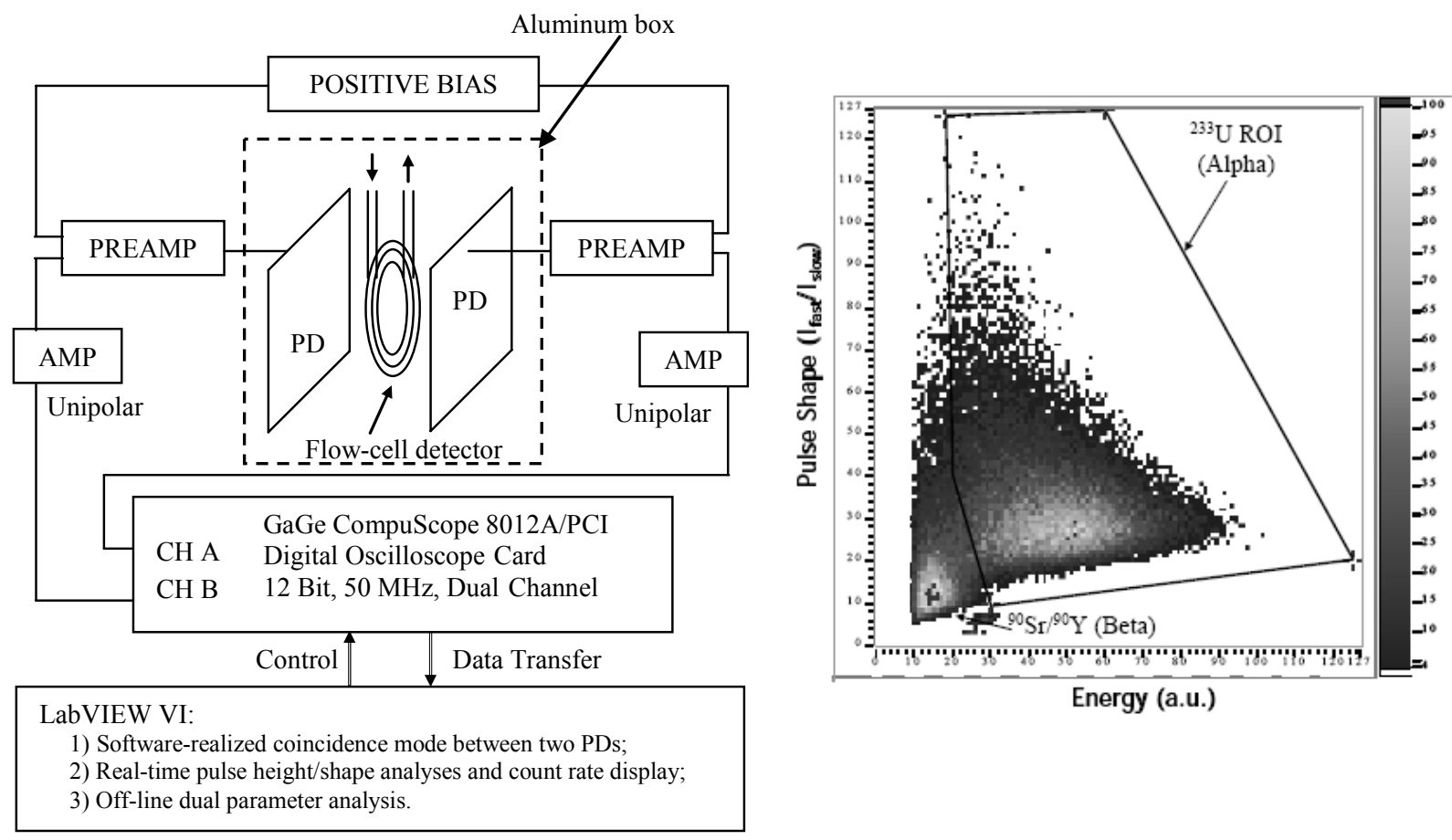

A

B

Figure 6. A. Schematic of the scintillation detection system using silicon photodiode detectors. B. Dual parameter histogram of CsI:Tl flow-cell radiation detector excited by ${ }^{233} \mathrm{U}$ (alpha) and ${ }^{90} \mathrm{Sr} /{ }^{90} \mathrm{Y}$ (beta) demonstrating simultaneous detection and separation of alpha and beta events.

\section{Approach \\ Digital Signal Processing}

- Digital data acquisition systems were used to record and process individual detection pulses

- Several software algorithms were developed and optimized to execute pulse shape and pulse height processing of signals to separate individual radiation events.

\section{Successes}

- Using a combination of plastic and inorganic scintillators, a digital signal processing system was successfully applied to the simultaneous detection of beta and gamma events.

- A new digital signal processing algorithm using an inverse of pulse shape parameter was developed and successfully demonstrated that significantly improved pulse shape discrimination capabilities relative to existing methods.

- This work is relevant to designing advanced flow detectors capable of detecting beta emitters in the presence of a gamma radiation field.

Pulse shape discrimination (PSD) is an important method employed for identification of the radionuclides of interest in the presence of unwanted background radiation. The information from the shape of the pulse is used to discriminate between the pulses of interest from the background events. Traditionally the discrimination is based on the difference in the shape of the analog pulse of different radiations from a phoswich detector (two scintillators with large difference in decay times used 
simultaneously) or by using an appropriate inorganic scintillator which has fast and slow decay components.

Our current research is based on the use of the digital signal processing techniques to compare the pulse shape discrimination methods and identify the best method for use in process analyzers. Moreover, we were successful in developing new methods which provide improved signal discrimination performance. Our work to date has been focused on using a BC400 $(2.5 \times 1.2 \mathrm{~cm})$ plastic and bismuth germanate $(\mathrm{BGO})(2.5 \times 2.5 \mathrm{~cm})$ inorganic scintillator phoswich detector system for detection of beta emitters in the presence of gamma radiation. The beta-gamma pulse shape discrimination is studied using the phoswich detector system with ${ }^{137} \mathrm{Cs}(1 \mu \mathrm{Ci})(\mathrm{E} \gamma=662 \mathrm{keV}$ gamma $)$ and ${ }^{90} \mathrm{Sr} /{ }^{90} \mathrm{Y}(0.1 \mu \mathrm{Ci})$ $\left(E_{\beta, \max }=546 / 2281 \mathrm{keV}\right)$. The pulses are integrated by a voltage sensitive preamplifier with large shaping time and then digitized at $40 \mathrm{MHz}$ using a 4 Channel Digital Gamma Finder module (DGF-4C) from XRay Instrumentation Associates.

PSD algorithms using rise time, zero-crossing, charge comparison, and constant discrimination methods to obtain pulse shape parameters used for signal discrimination were investigated. A new approach using inverse value of the pulse shape parameters was conceptualized and successfully demonstrated that resulted in a 3 fold enhancement of the figure of merit for discrimination of gamma events relative to existing methods. Digital PSD approach is particularly promising in designing efficient guard systems for low-level detection of beta-emitters in the process analyzers that typically must operate under elevated background conditions.

\section{Simulation of the Solid Scintillator Flow Cells Approach}

- Energy deposition and light collection efficiency in solid scintillator flow cell was successfully modeled to gain fundamental understanding of the processes that determine detection efficiency

- This information is important to optimize detection of ${ }^{99} \mathrm{Tc}$ and ${ }^{90} \mathrm{Sr}$ in process analyzer instruments

\section{Successes}

- Energy deposition and light collection in solid scintillator flow cells were successfully simulated using Monte Carlo methods.

- Simulation results were compared with experimental measurements

- Important trade off parameters relevant to flow-cell design were identified

Understanding of the energy deposition and light collection efficiencies in the solid scintillator cells is important to selecting optimal parameters for flow detection cells used in the process analyzers. We conducted simulations of the energy deposition processes using Monte Carlo code as relevant for detection of beta emitters in liquid samples. The effects of the scintillator particle size, scintillator density and beta particle energy were successfully modeled and compared with the experimental data. Simulation results showed that higher packing density and smaller particle size generally result in higher geometrical detection efficiency. These effects were especially significant for the beta particle energies below 180 $\mathrm{keV}$. Initial modeling of the light collection efficiency in solid scintillator cells was conducted using Monte Carlo methods. Effects of index of refraction of the liquid sample and number of layers of scintillator in the cell were investigated. Light collection efficiency decreased with the number of scintillator particle layers. The discrepancies between experimental values and simulation results were observed initially and are likely due to the current small scale of the simulation. A scale up of the model using most recent version of the optical transport code DETECT 2000 remains to be performed and is expected to result in better agreement between simulation and experiment. 


\section{LITERATURE CITED}

[1] Egorov, O.B., et al., "Sequential Injection System with Stopped Flow Radiometric Detection for Automated Analysis of 99Tc in Nuclear Waste", Anal. Chem., 1998, 70, p. 977-984.

[2] Blanchard, D.L., et al., "Technetium in Alkaline, High-Salt, Radioactive Tank Waste Supernate: Preliminary Characterization and Removal",PNNL-11386, 1997, Pacific Northwest National Laboratory, Richland, WA.

[3] Kurath, D.E., D.L. Blanchard, and J.R. Bontha, "Ion Exchange Distribution Coefficients for Cs and Tc removal from Hanford Wank Supernatants AW-101 (Envelope A) and AN-107 (Envelope C)," BNFL-RPT009, 1999, Pacific Northwest National Laboratory, Richland, WA.

[4] Chamberlin, R.M., et al., "Radioanalytical methods in the discovery and characterization of nonpertechnetate $\left({ }^{99} \mathrm{Tc}\right.$ ) species in hanford tank wastes", ACS Symposium Series, 2004, 868(Radioanalytical Methods in Interdisciplinary Research), p. 177-192.

[5] Schroeder, N.C., et al., "Technetium oxidation state adjustment for Hanford waste processing", Science and Technology for Disposal of Radioactive Tank Wastes, [Proceedings of the American Chemical Society Symposium on Science and Technology for Disposal of Radioactive Tank Wastes], Las Vegas, Nev., Sept. 7-11, 1997, 1998, p. 301-320.

[6] Schroeder, N.C., et al., "Feed adjustment chemistry for Hanford 101-SY and 103-SY tank waste: attempts to oxidize the non-pertechnetate species", J. Radioanal. Nucl. Chem., 2001, 250(2), p. 271-284.

[7] Nevissi, A.E., et al., "Radiochemical Determination of Technetium-99", J. Radioanal. Nucl. Chem., 1994, 177(1), p. 91-99.

[8] Egorov, O.B. and D.E. Kurath, "Automated 99Tc Analysis in AW-101 and AN-107 "Diluted Feed Matrixes", PNWD-3014, 2000, Battelle, Richland.

[9] Goulden, P.D. and D.H.J. Anthony, "Kinetics of uncatalyzed peroxydisulfate oxidation of organic material in fresh water", Anal. Chem, 1978, 50(7), p. 953-8.

[10] Cotton, F.A.W., G., "Advanced Inorganic Chemistry", 5th edition ed. 1988, New York: John Wiley \& Sons.

[11] Egorov, O.B., M.J. O'Hara, and J.W. Grate, Microwave-Assisted Sample Treatment in a Fully Automated Flow-Based Instrument: Oxidation of Reduced Technetium Species in the Analysis of Total Technetium-99 in Caustic Aged Nuclear Waste Samples. Anal. Chem., 2004. 76: p. 3869-3877.

[12] Gedye, R., "Microwave-enhanced chemistry, fundamentals, sample preparation and applications, edited by H. M. Kingston and Stephen J. Haswell", J. Am. Chem. Soc., 1999, 121(19), p. 4729.

[13] Kingston, H.M. and S.J. Haswell, "Microwave-Enhanced Chemistry: Fundamentals, Sample Preparation, and Applications". 1997, Washington, D.C.: American Chemical Society, 772 pp.

[14] Mermet, J.M., "Focused-microwave-assisted reactions", in Microwave-Enhanced Chemistry: Fundamentals, Sample Preparation, and Applications, H.M. Kingston and S.J. Haswell, Editors. 1997, American Chemical Society: Washington, D.C., p. 371-400.

[15] Richter, R.C., D. Link, and H.M. Kingston, "Microwave-enhanced chemistry", Anal. Chem., 2001, 73(1), p. 31A-37A.

[16] Mena, M.L., et al., "Fast on-line selenium determination in enriched yeast slurry by microwave digestion-hydride generation-atomic absorption spectroscopy", Laboratory Automation and Information Management, 1999, 34(2), p. 159-165.

[17] Caballo-Lopez, A. and M.D. Luque de Castro, "Slurry Sampling-Microwave Assisted Leaching Prior to Hydride Generation-Pervaporation-Atomic Fluorescence Detection for the Determination of Extractable Arsenic in Soil", Anal. Chem., 2003, 75(9), p. 2011-2017.

[18] Gurleyuk, H., J.F. Tyson, and P.C. Uden, "Determination of extractable arsenic in soils 
using slurry sampling-on-line microwave extraction-hydride generation-atomic absorption spectrometry", Spectrochimica Acta, Part B: Atom. Spectr., 2000, 55B(7), p. 935-942.

[19] Thomas, P., J.K. Finnie, and J.G. Williams, "Feasibility of identification and monitoring of arsenic species in soil and sediment samples by coupled HPLC- inductively coupled plasma mass spectrometry", J. Anal. Atom. Spectr., 1997, 12(12), p. 1367-1372.

[20] Arruda, M.A.Z., M. Gallego, and M. Valcarcel, "Semi-online microwave-assisted digestion of shellfish tissue for the determination of selenium by electrothermal atomic absorption spectrometry", $J$. Anal. Atom. Spectr., 1996, 11(2), p. 169-73.

[21] Burguera, J.L., et al., "Flow injection for the determination of Se(IV) and Se(VI) by hydride generation atomic absorption spectrometry and microwave oven online prereduction of $\mathrm{Se}(\mathrm{VI})$ to Se(IV)", Spectrochim. Acta,B, , 1996, 51B(14), p. 1837-1847.

[22] Eva Moreno, M., C. Perez-Conde, and C. Camara, "Speciation of inorganic selenium in environmental matrices by flow injection analysis-hydride generation-atomic fluorescence spectrometry. Comparison of offline, pseudo on-line and on-line extraction and reduction methods", J. Anal. Atom. Spectr., 2000, 15(6), p. 681-686.

[23] He, Y., et al., "Completely integrated online determination of dissolved selenium(IV) and total inorganic selenium in sea-water by flow injection hydride generation atomic fluorescence spectrometry", J. Anal. Atom. Spectr., 1998, 13(11), p. 1291-1296.

[24] de Andrade, J.C., J.C. Rocha, and N. Baccan, "Sequential spectrophotometric determination of chromium(III) and chromium(VI) using flow injection analysis", Analyst, 1985, 110, p. 197-199.

[25] Blanchard, D.L., D.E. Kurath, and B.M. Rapko, Small column Testing of Superlig-639 for Removing ${ }^{99}$ Tc from Hanford Tank Waste Envelope C (Tank 241-AN-107). 2000, Richland, WA. [26] Lukens, W.W., et al., "Identification of the Non-Pertechnetate Species in Hanford Waste Tanks, Tc(I)Carbonyl Complexes", Environ. Sci. Tech., 2004, 38(1), p. 229-233.

[27] Skoog, D.A. and D.M. West, "Fundamentals of Analytical Chemistry". 1982, Philadelphia: CBS College Publishing.

[28] Pichler, U., et al., "Microwave-Enhanced Flow System for High-Temperature Digestion of Resistent Organic Materials", Anal. Chem., 1998, 71, p. 4050-4055.

[29] Burguera, J.L., M. Burguera, and C. Rondon, "An on-line flow-injection microwave-assisted mineralization and a precipitation/dissolution system for the determination of molybdenum in blood serum and whole blood by electrothermal atomic absorption spectrometry", Talanta, 2002, 58(6), p. 1167-1175.

[30] Burguera, M. and J.L. Burguera, "Microwave-assisted sample decomposition in flow analysis", Anal.Chim. Acta, 1998, 366(1-3), p. 63-79.

[31] Gallignani, M., et al., "A time-based flow injection-cold vapor-atomic absorption spectrometry system with online microwave sample pre-treatment for the determination of inorganic and total mercury in urine", Anal.Chim. Acta, 1998, 369(1-2), p. 57-67.

[32] Huang, C.-C., M.-H. Yang, and T.-S. Shih, "Automated Online Sample Pretreatment System for the Determination of Trace Metals in Biological Samples by Inductively Coupled Plasma Mass Spectrometry", Anal. Chem., 1997, 69(19), p. 3930-3939.

[33] Stewart, L.J.M. and R.M. Barnes, "Flow-through, microwave-heated digestion chamber for automated sample preparation prior to inductively coupled plasma spectrochemical analysis", Analyst, 1994, 119(5), p. 1003-10.

[34] Flock, J., F. Michael, and K.D. Ohls, "An open microwave digestion of oxide materials continuously analyzed by ICP emission spectrometry", Fres' J. Anal. Chem, 1999, 363(3), p. 306-310.

[35] Urie, M.W., et al., "Inorganic and Radiochemical Analysis of AW-101 and AN-107

"Diluted Feed" Materials", PNWD-2463, 1999, Battelle, Pacific Northwest Division, Richland,

WA.

[36] Washington Group International, P.T.D., "Selection of the total Tc monitor technology for deployment at WTP at Hanford", Review and Approval Documentation, Richland, WA, 2004. 